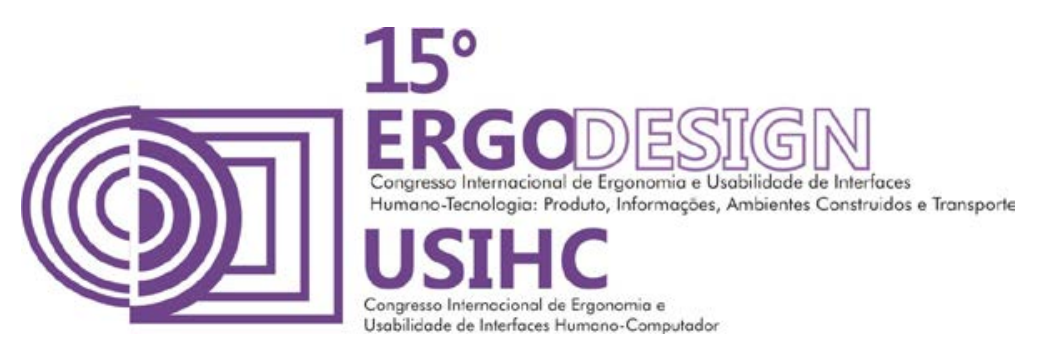

\title{
QUALIDADE ESPACIAL DO AMBIENTE EDUCACIONAL: AVALIAÇÃO ATRAVÉS DE MULTIMÉTODOS
}

\section{SPATIAL QUALITY OF SCHOOL ENVIRONMENT: EVALUATION THROUGH MULTIMETHOD}

MONTANHEIRO, Fabiana Padilha (1);

MATTOS, Karina Andrade (2);

DIAS, Edmilson Queiroz (3);

FONTES, Maria Solange Gurgel de Castro (4);

MAGAGNIN, Renata Cardoso (5)

(1) Universidade Estadual Paulista, Mestranda

e-mail: fpmontanheiro@yahoo.com.br

(2) Universidade Estadual Paulista, Arquiteta e Urbanista

e-mail: karina amattos@hotmail.com

(3) Universidade Estadual Paulista, Mestrando

e-mail: edmilsonqueirozdias@gmail.com

(4) Universidade Estadual Paulista, Doutora

e-mail: sgfontes@faac.unesp.br

(5) Universidade Estadual Paulista, Doutora

e-mail: $\underline{\text { magagnin@faac.unesp.br }}$

\begin{abstract}
RESUMO
Este artigo apresenta a Avaliação Pós Ocupação (APO) de um ambiente de educação infantil utilizando uma abordagem multimétodos (entrevistas, questionários, walkthrough e vistoria técnica). O objetivo foi comparar o desempenho de cada método na identificação dos aspectos positivos e negativos deste ambiente. As entrevistas e questionários permitiram entender o funcionamento da escola e a satisfação dos usuários. O walkthrough e a vistoria técnica contribuíram para aferir o desempenho funcional, estético, ambiental, entre outros aspectos. Os resultados mostraram que os métodos utilizados se complementam e são imprescindíveis na avaliação do ambiente escolar visando subsidiar a qualidade espacial nos projetos de intervenção.
\end{abstract}

Palavras-chave: Avaliação Pós-Ocupação (APO), escola infantil, qualidade espacial 


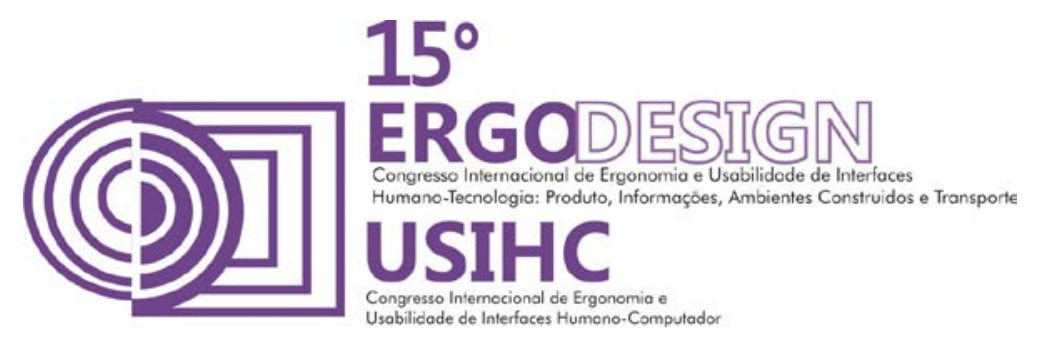

\begin{abstract}
This article shows a Post Occupancy Evaluation (POE) of an early childhood education environment using a multimethod approach (interviews, questionnaires, walkthrough and technical inspection). The objective was to compare the performance of each method to identify the positive and negative aspects of the environment. Interviews and questionnaires allowed understanding of the school's operation and user satisfaction. Have the walkthrough and the technical inspection contributed to assess functional performance, aesthetic, environmental, among others. The results showed that the methods used are complementary and are essential in assessing the school environment in order to support the spatial quality of intervention projects.
\end{abstract}

Keywords: Post Occupancy Evaluation (POE), childhood education schools, spatial quality

\title{
1. INTRODUÇÃO
}

Nos ambientes educacionais é necessário identificar parâmetros importantes que ofereçam condições para o desenvolvimento infantil nos aspectos físico, psicológico, intelectual e social. De acordo com Brasil (2006), esses aspectos constituem requisitos essenciais para a formulação de ambientes de qualidade destinados à Educação Infantil. Campos e Rosemberg (2009) ressaltam também que esses ambientes devem se aconchegantes, seguros e estimulantes e que proporcionem um contato com a natureza.

Contudo, muitos edifícios destinados à educação infantil apresentam problemas que podem comprometer o desenvolvimento infantil, muitos dos quais relacionados com a qualidade espacial. De acordo com Brasil (2006), mais de $70 \%$ dos problemas nos ambientes educacionais são decorrentes de falhas de projeto e de execução do edifício. Assim, o uso de metodologias de avaliação pós-ocupação em edificações destinadas à educação infantil pode constituir em uma importante ferramenta a ser aplicada na fase da concepção das diretrizes de projeto, visando ampliar a qualidade espacial dessas edificações.

A Avaliação Pós-Ocupação (APO), segundo Rómero e Ornstein (2003), diz respeito a uma série de métodos e técnicas que "diagnosticam fatores positivos e negativos do ambiente no decorrer do uso a partir da análise de diferentes fatores". Dessa forma, esses autores afirmam que a APO se constitui uma base para a elaboração e desenvolvimento de edifícios melhores, pois se trata de um instrumento de controle de qualidade.

A APO é fundamental para aferir o atendimento das necessidades dos usuários, pois leva em consideração as suas necessidades, incorporando o ponto de vista dos avaliadores, projetistas e clientes. Através destas metodologias é possível identificar diversos problemas espaciais, melhorar o desempenho dos futuros projetos ou intervenções, e compreender quais são as alterações projetuais ou problemas de apropriação espacial necessárias, visando melhorar a concepção e a qualidade espacial do ambiente escolar.

Ornstein e Martins (1997), Issa; Poltronieri; Ornstein (2008), Rodrigues (2006) e Brasil (2006) dentre outros autores têm contribuído com estudos de APO em ambientes de educação infantil. Estas pesquisas comprovam que a APO contribui significativamente para aferir as condições de funcionamento das escolas em relação às suas características físicas e de usabilidade.

Nesse contexto, este artigo tem como objetivo identificar a qualidade espacial de um ambiente de educação infantil utilizando instrumentos de Avaliação Pós Ocupação (APO) e comparar o desempenho da abordagem multimétodos (entrevistas, questionários, walkthrough e vistoria técnica) na identificação dos aspectos positivos e negativos deste ambiente. 


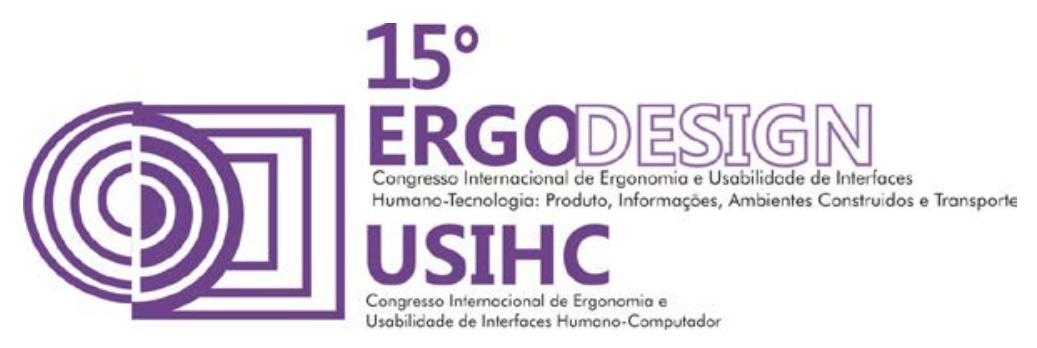

\section{ESTUDO DE CASO}

O objeto de estudo deste artigo foi analisar a Escola Municipal de Educação Infantil, EMEI "Stélio Machado Loureiro", na área central da cidade de Bauru, SP (Figura 1). Atualmente, a EMEI oferece a seus alunos três períodos de funcionamento manhã, tarde e integral, distribuídos entre: Maternal I, II e III e, Jardins I, II e III. Com 14 funcionários, entre diretora, professoras, auxiliares, cuidadoras e serventes, a escola atende atualmente 114 crianças com idade entre 1 ano e 8 meses a 5 anos.

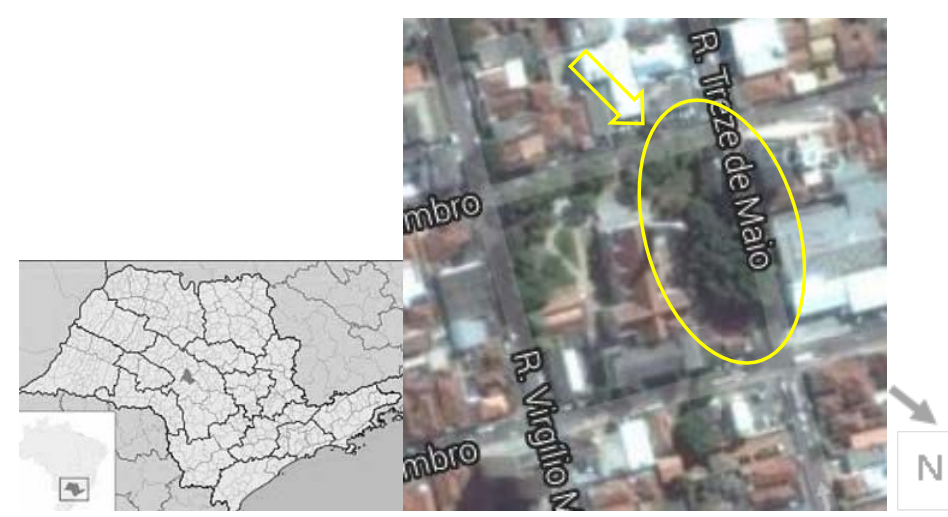

Figura 1 - Mapa da cidade de Bauru (SP) e a localização da escola na quadra. Fonte: https://www.google.com.br/maps/. Acesso em 08/01/2015.

A EMEI possui três salas de aula, sendo uma delas denominada de "sala do soninho", sala dos professores, biblioteca, diretoria, refeitório, cozinha e banheiros, distribuídos em um único pavimento térreo com área total de $415,00 \mathrm{~m}^{2} \mathrm{em}$ um terreno de $1.270,00 \mathrm{~m}^{2}$. Além de um pátio descoberto e um playground, distribuídos em uma extensa área externa (Figura 2).

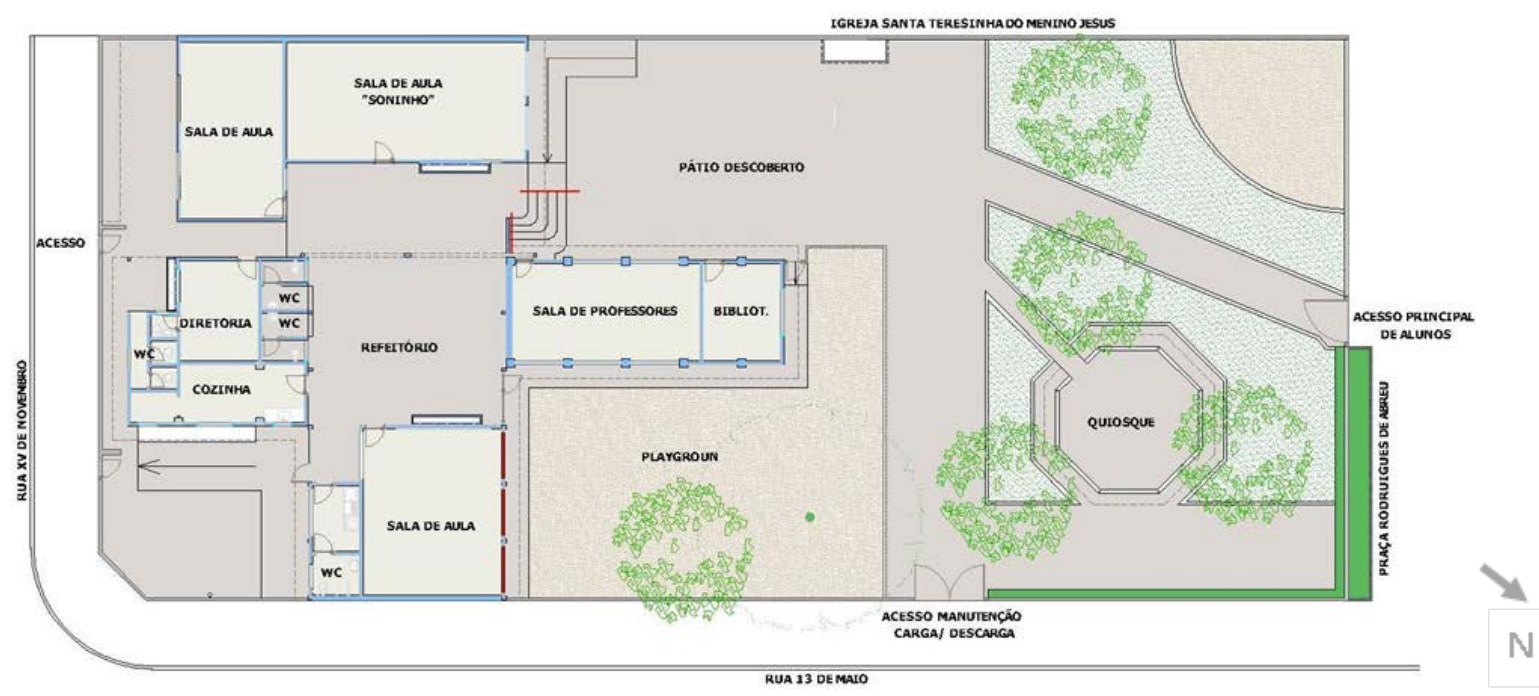

Figura 2 - Planta da Escola

Fonte: Prefeitura Municipal de Bauru (2001); adaptado pelos Autores (2014), sem escala. 


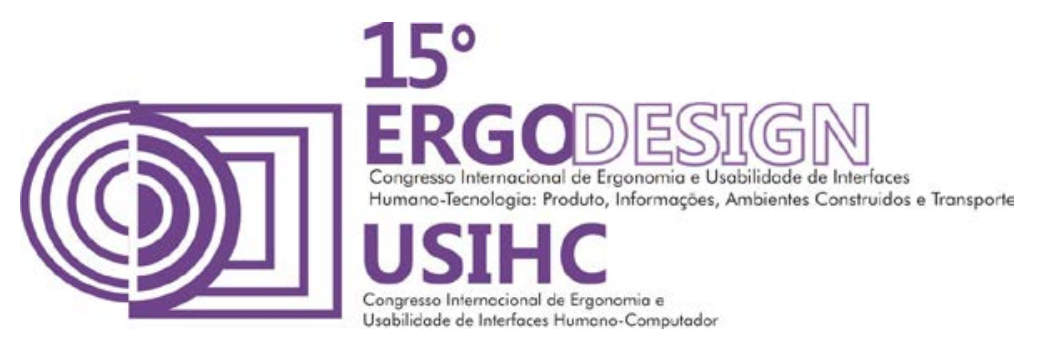

\section{METODOLOGIA}

Para atender aos objetivos deste trabalho foram adotados os seguintes instrumentos de avaliação: Entrevista, Questionário, Walkthrough e Vistoria Técnica.

Para conhecer preliminarmente os pontos positivos e negativos da escola foi realizada uma entrevista informal com a Diretora da Escola. Em seguida foi realizado o walkthrough, que segundo Rheingantz et al (2009), é um método que combina simultaneamente uma observação com uma entrevista, muito utilizado na avaliação de desempenho do ambiente construído e na programação arquitetônica, pois possibilita a identificação descritiva dos aspectos negativos e positivos dos ambientes analisados. Na terceira etapa da pesquisa foi aplicado um questionário contendo perguntas fechadas, com opções de múltipla escolha, dirigidos aos professores e funcionários. No total, participaram desta etapa 14 pessoas.

O questionário foi dividido em três etapas. A primeira etapa consistiu na definição das características pessoais dos entrevistados (idade, sexo, nível de instrução, tempo de serviço, entre outros aspectos) que possibilitou traçar um perfil dessas pessoas. A segunda fase referiuse a avaliação da escola de um âmbito geral e a terceira fase consistiu na análise dos ambientes de forma individual (áreas externas e de convivência; pátio coberto e descoberto, Áreas administrativas, Cozinha, Biblioteca e Salas de Aula).

Nestas duas etapas, cada questão pode ser avaliada utilizando a seguinte escala de valores: muito ruim (1), ruim (2), relativamente ruim (3), relativamente bom (4), bom (5) e muito bom (6), sendo ainda atribuída uma cor que variou do vermelho escuro, vermelho, amarelo escuro, amarelo, verde e verde escuro (ver Figura 3). A partir da avaliação numérica de cada avaliador foi realizado o cálculo da média aritmética para cada item avaliado, que possibilitou identificar qual atributo foi melhor avaliado na percepção do usuário da escola, e assim identificar qual ou quais ambientes eram mais problemáticos.

\begin{tabular}{|c|c|c|}
\hline MUITO RUIM & 1 & MR \\
\hline RUIM & 2 & $\mathrm{R}$ \\
\hline RELATIVAMENTE RUIM & 3 & $\mathrm{RR}$ \\
\hline RELATIVAMENTE BOM & 4 & $\mathrm{RB}$ \\
\hline $\mathrm{BOM}$ & 5 & B \\
\hline MUITO BOM & 6 & MB \\
\hline
\end{tabular}

Figura 3 - Escala de valores

Posteriormente foi realizado o método da Vistoria Técnica a partir de um checklist que permitiu avaliar os seguintes aspectos: i) Estético-compositivos (aparência externa, aparência interna, imagem, cores, texturas, formas, proporções, símbolos, princípios propositivos e padronização); ii) Técnico-construtivos (manutenção e durabilidade, materiais, racionalidade, qualidade do revestimento, aparência do revestimento e estratégias de conforto ambiental); iii) Contextual-ambiental (tráfego, acesso, localização, paisagismo, topografia, vizinhança, qualidade do ar, ventilação, acústica, sombreamento das aberturas, temperatura e iluminação) e; iv) Programático-funcional (Setor pedagógico, setor administrativo, setor de convivência, organização espacial, recreação, vivência, circulações, acessos principais, acessibilidade, possibilidade de expansão, mobiliário e layout, segurança, comunicação visual, integração interior e exterior, estacionamento e vandalismo). Cada item foi avaliado através da seguinte escala de valores: muito bom (MB), relativamente bom (RB), relativamente ruim (RR), muito ruim (MR) e não se aplica (NA). 


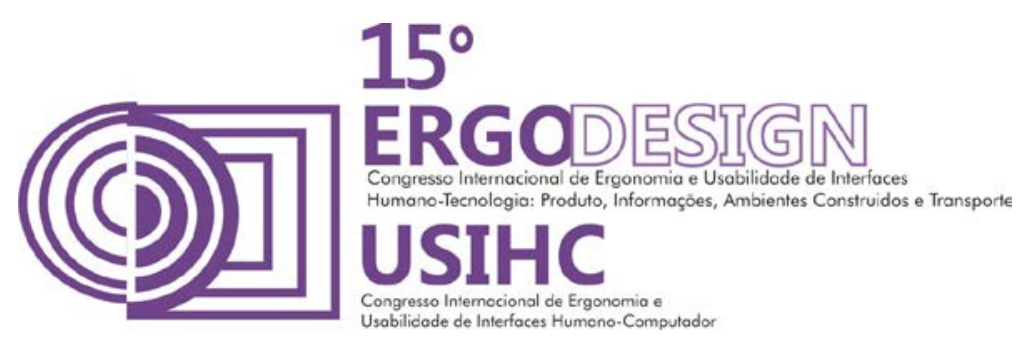

\section{RESULTADOS}

O conjunto de instrumentos empregados da metodologia de APO possibilitou avaliar os desempenhos: funcional, estético e técnico, e assim, aferir os diversos problemas da escola. Além de ter sido imprescindível para a identificação do método mais eficiente para a avaliação.

\subsection{Entrevista}

A partir da entrevista realizada com a Diretora foram identificados os seguintes problemas: i) de ordem funcional, relacionado com a distância dos banheiros com as salas de aula e a proximidade do banheiro infantil feminino com um dos portões de acesso a entrada principal da escola; ii) ruído e segurança - em relação ao grande tráfego de automóveis no entorno, que contribuiu a alteração da entrada principal dos alunos; iii) ausência de cobertura entre as salas e a entrada dos alunos.

\subsection{Questionários}




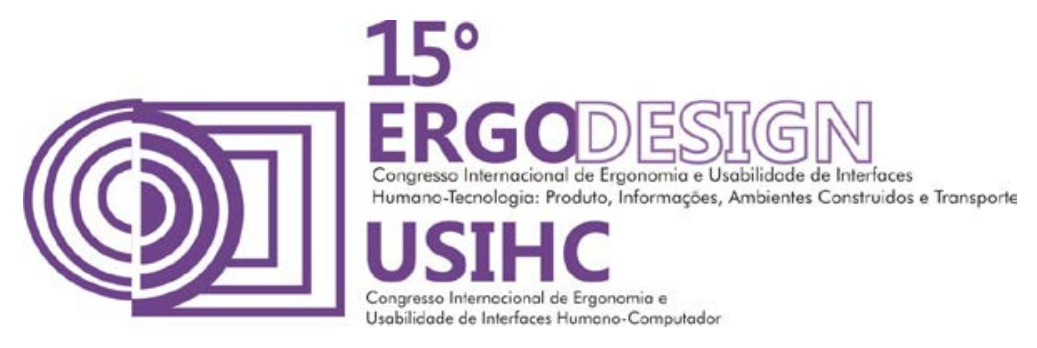

Para avaliar o âmbito geral da escola foi aplicado um questionário. Dos vinte e oito elementos avaliados, $57,1 \%$ das respostas indicaram uma boa avaliação, ou seja, foram atribuídas notas que variaram de $\mathrm{B}(\mathrm{Bom}), \mathrm{RB}$ (Relativamente Bom) e B (Bom). Os aspectos melhor avaliados foram: aparência externa, sombreamento arbóreo, dimensões dos ambientes, mobiliário, flexibilidade dos espaços. Em relação aos itens que receberam pior avaliação (MR - Muito Ruim e R - Ruim), o percentual final foi de 67,9\%, que correspondeu aos seguintes aspectos: indicador de sustentabilidade; sinalização de saída de emergência, acessibilidade das pessoas com deficiência (Figura 4).

\section{Figura 4 - Gráfico com os resultados da avaliação dos aspectos gerais da escola}

Na sequência foi realizada a avaliação de cada ambiente (áreas externas e convivência, áreas administrativas, cozinha, biblioteca e salas de aula), individualmente. Os aspectos que receberam uma melhor avaliação (B - Bom, RB - Relativamente Bom e B - Bom), representaram $14,3 \%$ do total das questões avaliadas; o que correspondeu aos seguintes aspectos: nas áreas externas e de convivência: tamanho, barulho; na cozinha: a aparência; na

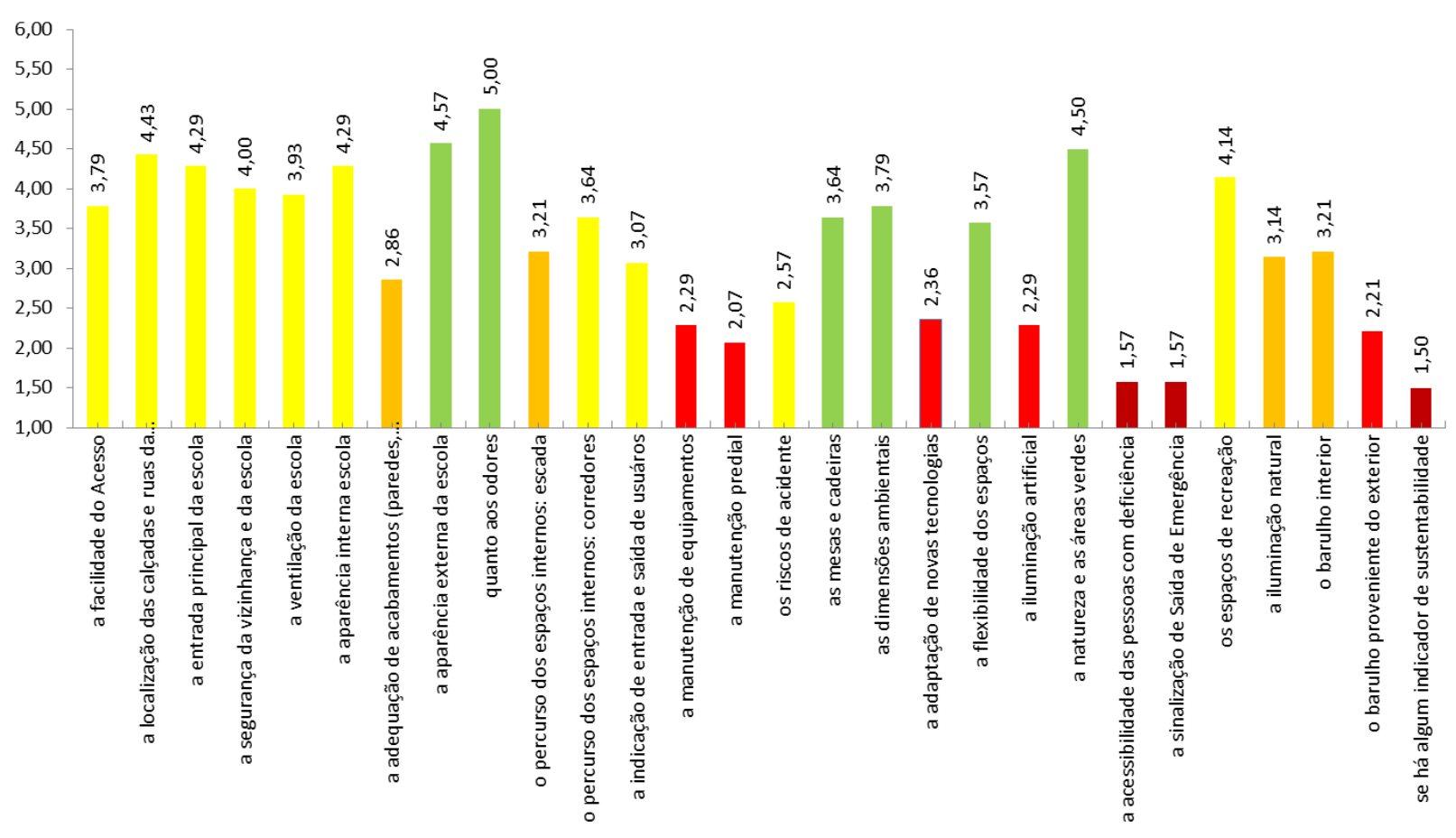

biblioteca e nas salas de aula: a temperatura (conforto térmico).

Ao analisar os itens que receberam uma pior avaliação (MR - Muito Ruim e R - Ruim), o percentual final correspondeu a $85,7 \%$ dos elementos avaliados, que correspondeu aos seguintes aspectos: aparência, temperatura, presença da natureza, iluminação, ventilação e privacidade das áreas externas e convivência, tamanho, aparência, temperatura, barulho, localização, iluminação, ventilação e mobiliário das áreas administrativas; tamanho, temperatura, barulho, localização, iluminação, ventilação e mobiliário da cozinha; tamanho, aparência, barulho, localização, iluminação, ventilação e mobiliário da biblioteca; acabamento, tamanho, aparência, barulho, localização, iluminação, ventilação e mobiliário das salas de aula (Figura 5). 

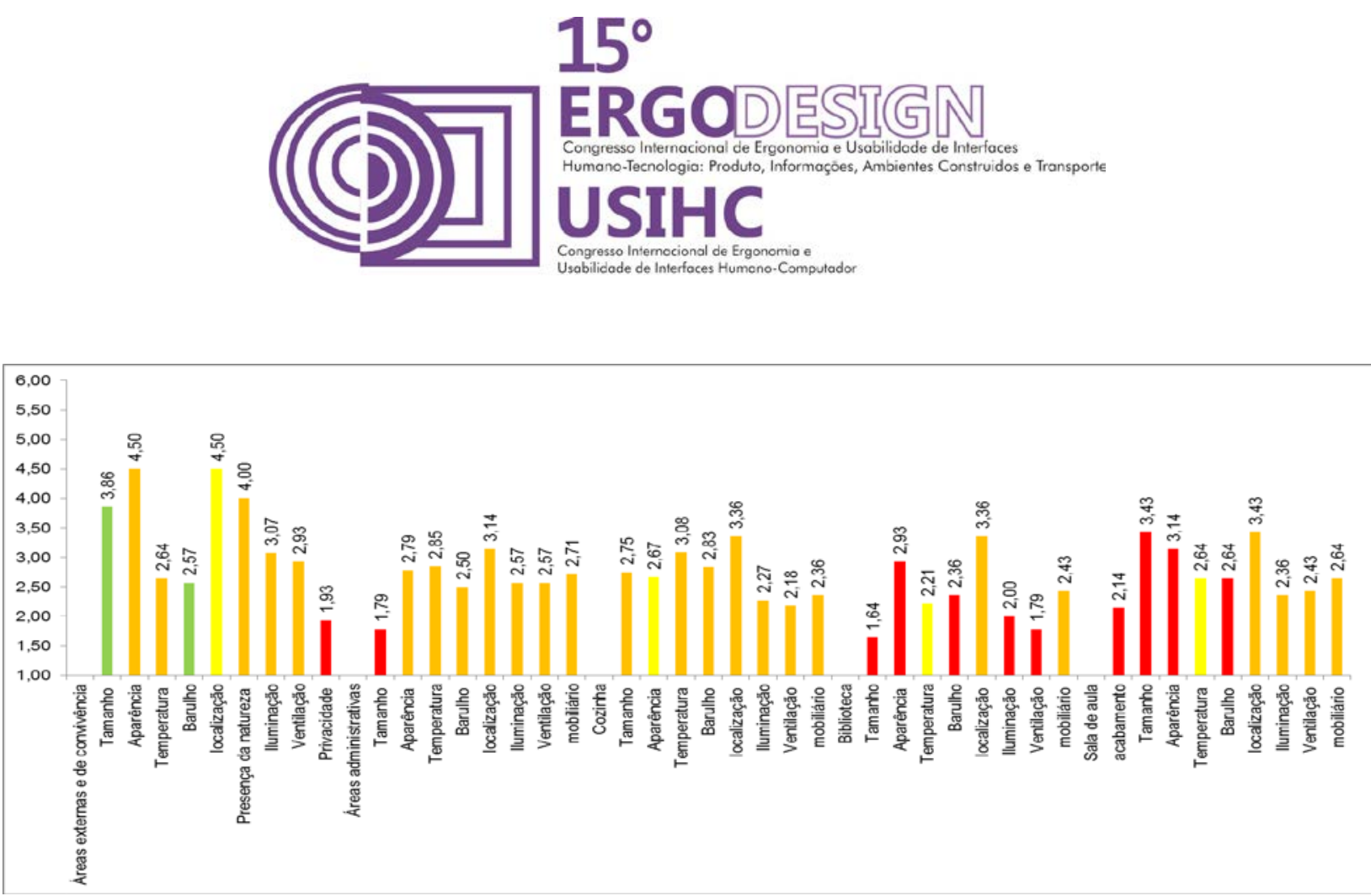

Figura 5 - Gráfico dos resultados da avaliação individual dos ambientes.

\subsection{Walkthrough}

A Figura 6 mostra o percurso desenvolvido através do walkthrough (passeio guiado) onde foi possível identificar os seguintes problemas: Acesso principal; localização do Banheiro Feminino; tamanho da biblioteca (Figura 7); calhas entupidas; infiltrações; entrada secundária (Figura 8); ausência de cobertura no pátio (Figura 9); problemas elétricos e falta de acessibilidade.

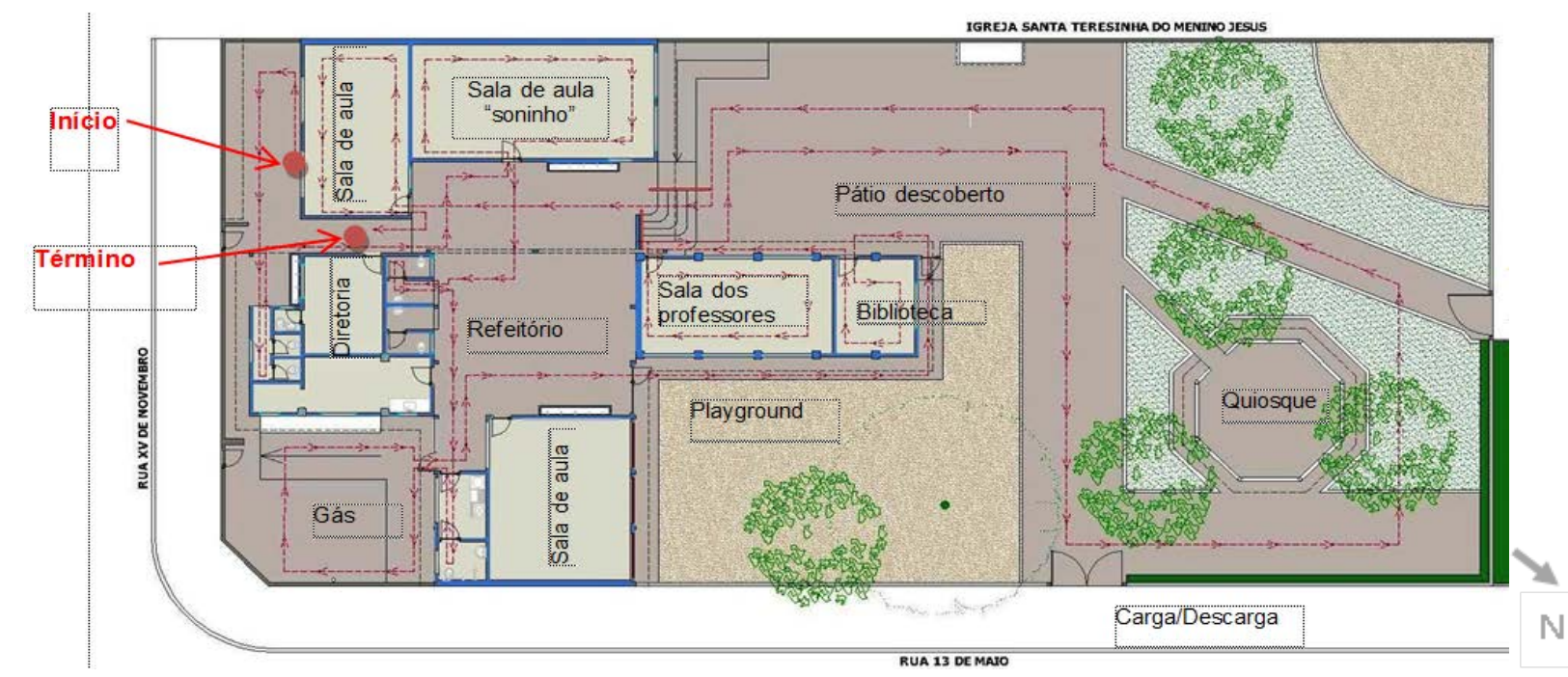

Figura 6 - Percurso desenvolvido durante o walkthrough (setas em vermelho).

Fonte: Prefeitura Municipal de Bauru (2001); adaptado pelos Autores (2014), sem escala. 


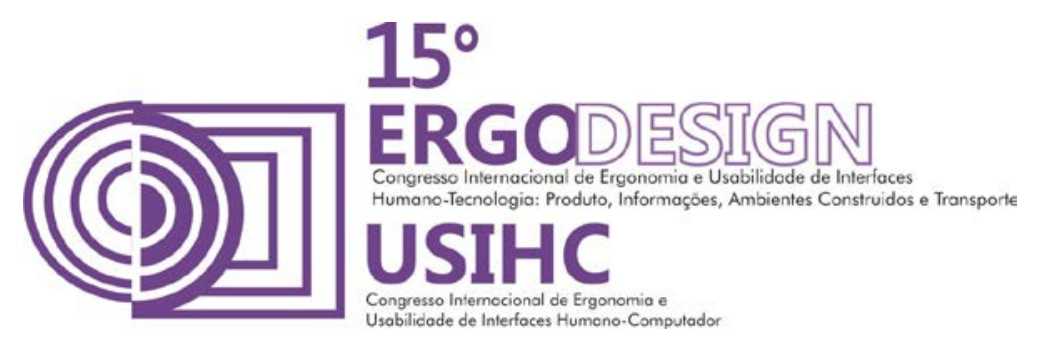

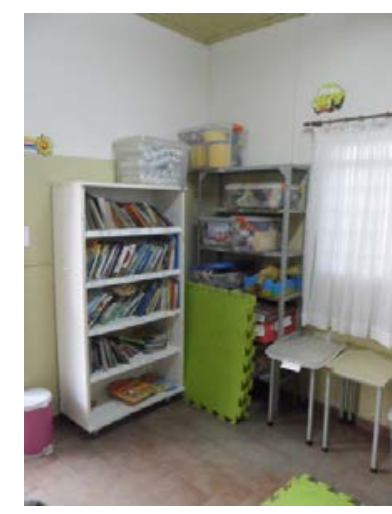

Figura 7 - Biblioteca

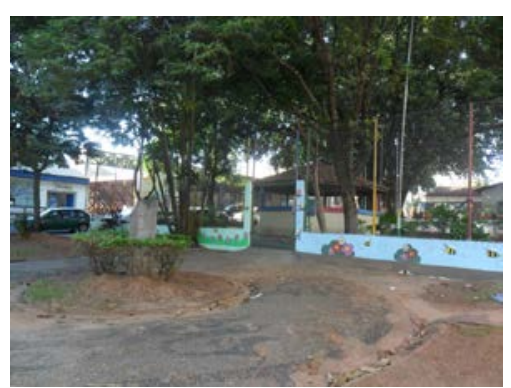

Figura 8 - Entrada secundária

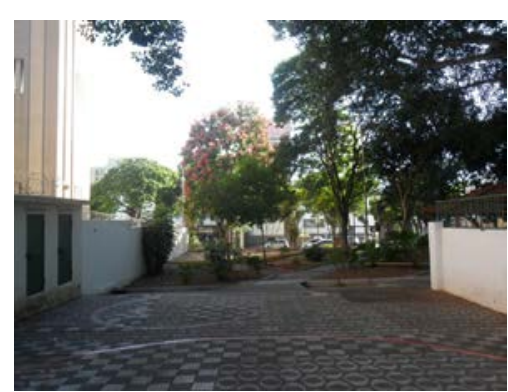

Figura 9 - Pátio descoberto

Em seguida, foi elaborado um mapa de problemas, onde os elementos analisados foram inseridos utilizando uma sequência numérica (1 a 12), conforme mostra a Figura 10.

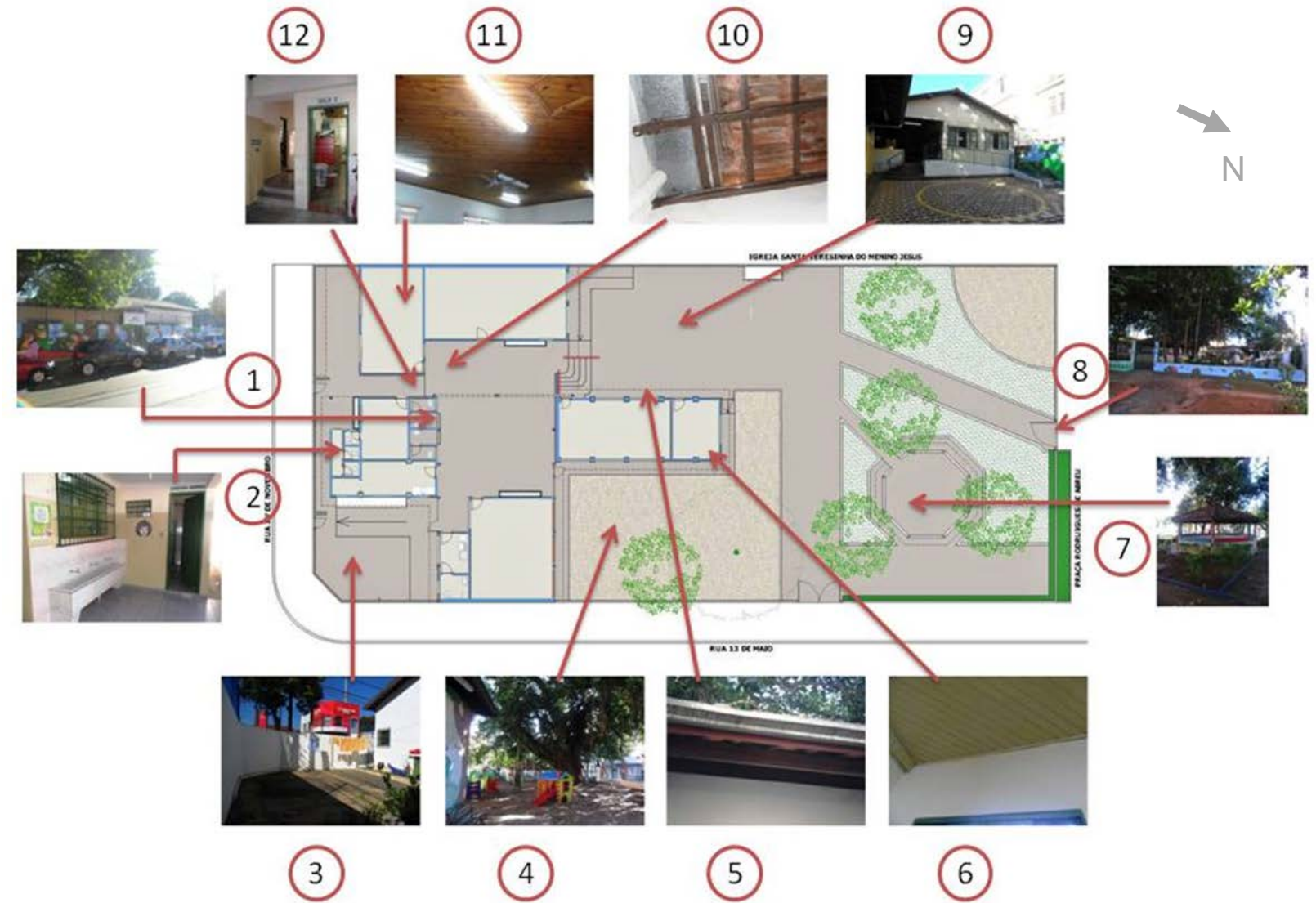

Figura 10 - Mapa de problemas

$\mathrm{Na}$ sequência são apresentadas as descrições de cada problema identificado na aplicação deste método.

1) Entrada da Rua XV de Novembro: Um dos principais problemas é o portão de acesso à escola pela Rua XV de Novembro. Por se tratar de uma área de grande fluxo de veículos e pedestres, o local já passou por problemas relacionados à segurança das crianças, pois o 


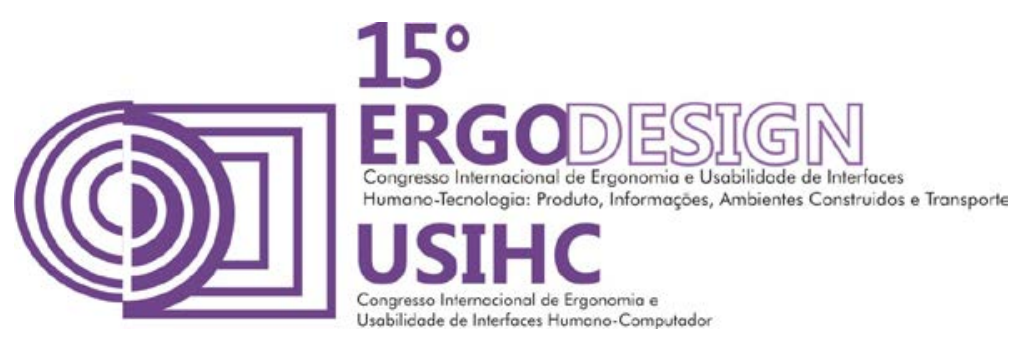

portão é de grade e o muro baixo. Uma nova grade foi instalada, contudo, houve a necessidade de desabilitar o banheiro feminino infantil - a proximidade com a rua deixava-o extremamente vulnerável. O portão permanece trancado sendo aberto somente quando solicitado e nos dias chuvosos, tornando-se o acesso dos alunos.

2) Banheiro Feminino: Muito próximo ao acesso principal da escola, o banheiro feminino foi desabilitado para o uso em função da segurança das meninas. Assim, um dos banheiros infantis masculino, localizado no pátio, cedeu-se ao uso feminino, não sendo suficiente para o número de alunos presentes.

3) Área inutilizada: Próxima à cozinha, uma área pouco utilizada pela presença de botijões de gás.

4) Playground Sombreado: Na área externa há problemas relacionados à sensação térmica. Trata-se de uma área "muito fria" durante o inverno devido à presença de árvores de grande porte.

5) Calhas entupidas: Um dos maiores problemas da escola são as calhas entupidas, provocadas pelo acúmulo de folhas, galhos e diversos tipos de materiais carregados pela chuva e pelo vento. O entupimento e a falta de manutenção das calhas resultam em problemas de infiltração no interior dos edifícios.

6) Infiltrações: Devido ao entupimento das calhas, são grandes os problemas de infiltração nos edifícios. Na biblioteca, por exemplo, o layout dos móveis foi modificado para que não houvesse danos aos livros adquiridos.

7) Quiosque: Assim como na área do playground, próximo ao quiosque existe muitas árvores de grande porte sombreando o local tornando no inverno a área "muito fria", impossibilitando a permanência das crianças.

8) Entrada Praça Rodrigues de Abreu: Devido ao intenso fluxo de carros na Rua XV de Novembro, por medidas de segurança, a entrada dos alunos foi transferida para outro portão, localizado na Praça Rodrigues de Abreu (ver Figura 1). Contudo, a distância desse acesso até as salas de aula e a ausência de cobertura entre as edificações se torna inviável em dias chuvosos.

9) Pátio Descoberto: O pátio descoberto é muito quente durante os dias de verão. Algumas atividades externas devem ser transferidas de local principalmente durante o período da tarde. A escola não possui uma quadra coberta para a prática de atividades esportivas.

10) Refeitório: Apresenta problemas de infiltração decorrente das calhas entupidas. Durante os dias chuvosos o piso precisa ser constantemente seco.

11) Problemas elétricos: As lâmpadas queimam com frequência, e só são substituídas com o auxílio dos pais dos alunos, responsáveis pela manutenção, assim como fazem com as calhas. Além disso, em uma das salas de aula foi detectado que algumas lâmpadas não acendem junto com as outras, prejudicando a iluminação do local.

12) Falta de acessibilidade: Um dos maiores problemas está em relação à acessibilidade. $O$ nível mais alto dos banheiros e das salas de aula em relação ao nível do pátio faz com que o acesso aos mesmos ocorra por meio de degraus, dificultando a locomoção tanto das crianças menores, quanto dos alunos com deficiência.

\subsection{Vistoria Técnica}

As características gerais do edifício foram avaliadas através de uma Vistoria Técnica. Ela foi 


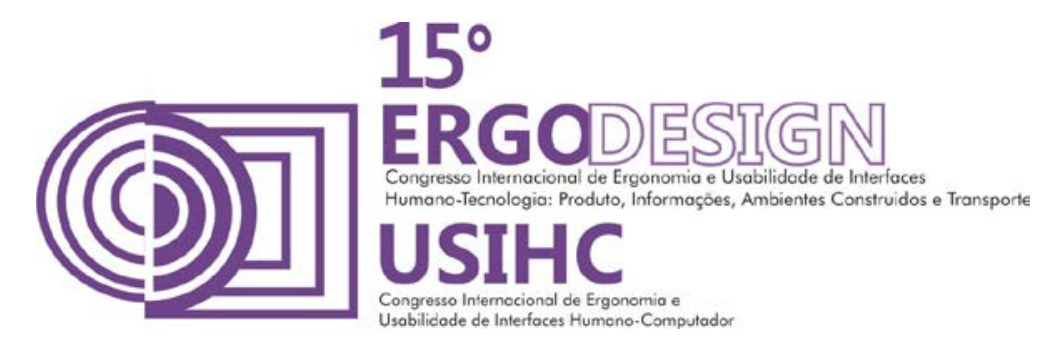

realizada utilizando como referência os aspectos: Estético-Compositivos; Técnico-construtivos; Contextual-Ambientais e Programático-Funcionais. Cada tema foi avaliado através de seus indicadores correspondentes, conforme mostra a Tabela 1.

Tabela 1 - Vistoria Técnica - checklist - Características Gerais do Edifício

\begin{tabular}{|c|c|c|c|c|c|c|}
\hline & Grau de avaliação & $\begin{array}{l}\text { MB-Muito } \\
\text { Bom }\end{array}$ & $\begin{array}{l}\text { RB-Rel. } \\
\text { Bom }\end{array}$ & $\begin{array}{l}\text { RR-Rel. } \\
\text { Ruim }\end{array}$ & $\begin{array}{l}\text { MR-Muito } \\
\text { Ruim }\end{array}$ & $\begin{array}{c}\text { NA-Não se } \\
\text { Aplica }\end{array}$ \\
\hline \multirow{10}{*}{ 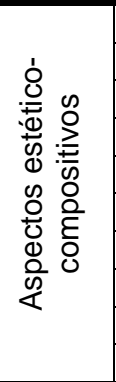 } & Aparência externa & & & & & \\
\hline & Aparência interna & & & & & \\
\hline & Imagem & & & & & \\
\hline & Cores & & & & & \\
\hline & Texturas & & & & & \\
\hline & Formas & & & & & \\
\hline & Proporções & & & & & \\
\hline & Símbolos & & & & & \\
\hline & Princípios propositivos & & & & & \\
\hline & Padronização & & & & & \\
\hline \multirow{6}{*}{ 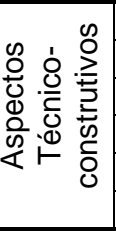 } & Manutenção/durabilidade & & & & & \\
\hline & Materiais & & & & & \\
\hline & Racionalidade & & & & & \\
\hline & Revestimento - qualidade & & & & & \\
\hline & Revestimento - aparência & & & & & \\
\hline & Estratégias de conforto ambiental & & & & & \\
\hline \multirow{12}{*}{ 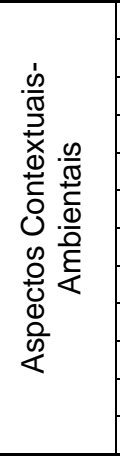 } & Tráfego & & & & & \\
\hline & Acesso & & & & & \\
\hline & Localização & & & & & \\
\hline & Paisagismo & & & & & \\
\hline & Topografia & & & & & \\
\hline & Vizinhança & & & & & \\
\hline & Qualidade do ar & & & & & \\
\hline & Ventilação & & & & & \\
\hline & Acústica & & & & & \\
\hline & Sombreamento das aberturas & & & & & \\
\hline & Temperatura & & & & & \\
\hline & Iluminação & & & & & \\
\hline \multirow{17}{*}{ 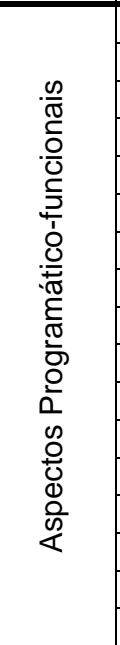 } & Setor pedagógico & & & & & \\
\hline & Setor administrativo & & & & & \\
\hline & Setor de serviços & & & & & \\
\hline & Setor de convivência & & & & & \\
\hline & Organização espacial & & & & & \\
\hline & Recreação & & & & & \\
\hline & Vivência & & & & & \\
\hline & Circulações & & & & & \\
\hline & Acessos Principais & & & & & \\
\hline & Acessibilidade & & & & & \\
\hline & Possibilidade de expansão & & & & & \\
\hline & Mobiliário/layout & & & & & \\
\hline & Segurança & & & & & \\
\hline & Comunicação Visual & & & & & \\
\hline & Integração interior e exterior & & & & & \\
\hline & Estacionamento & & & & & \\
\hline & Vandalismo & & & & & \\
\hline
\end{tabular}

Analisando os Aspectos Estético-Compositivos foi possível verificar que $70 \%$ dos itens avaliados corresponderam à avaliação: Muito Bom (MB) e Bom (B). Apenas 30\% receberam 


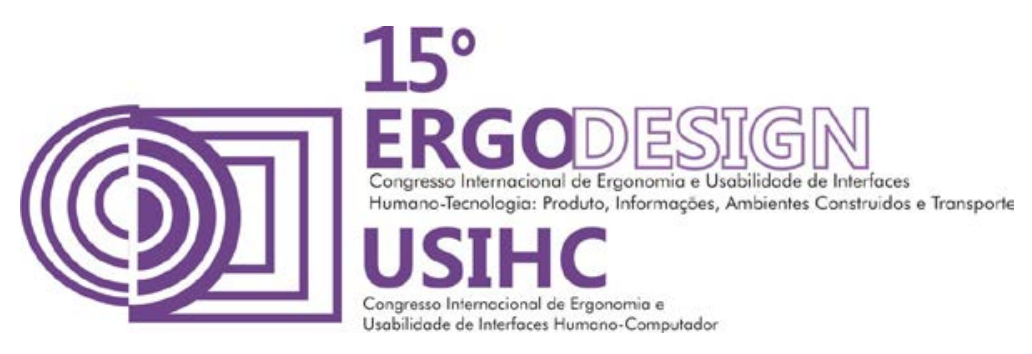

uma avaliação Ruim (R) - textura, forma e padronização. A maioria das escolas públicas são espaços sem qualidade espacial, pois são projetos padronizados que não levam em consideração qualquer particularidade; altera-se apenas a sua implantação no terreno.

Com relação aos Aspectos Técnico-Construtivos observou-se que $67 \%$ dos itens avaliados corresponderam à avaliação: Bom (B); e apenas 33\% receberam uma avaliação Ruim (R) Racionalidade e Estratégias de conforto ambiental. O material empregado nestas construções e a tecnologia utilizada, associado a padronização projetual tem contribuído para aumentar os problemas relacionados a manutenção destes edifícios e do conforto espacial.

Quanto aos Aspectos Contexto-Ambiental notou-se que 50\% dos itens avaliados foram bem avaliados, recebendo uma nota que variou de Muito Bom (MB) e Bom (B) e 50\% receberam uma avaliação Ruim (R) - Topografia, Vizinhança, Temperatura, lluminação e Sombreamento nas aberturas. Estes elementos são fundamentais para a melhoria da qualidade espacial dos edifícios escolares.

No que se refere aos Aspectos Programático-Funcional verificou-se que $47 \%$ dos itens avaliados referem-se a Muito Bom (MB) e Bom (B), 47\% correspondem a Ruim (RR) e Muito Ruim (MR) - setores pedagógico, administrativo e convivência, organização espacial, acessibilidade, mobiliário, segurança e integração interior/exterior e, menos de 1\% corresponde a Não Avaliado (NA) - Estacionamento, por não existir.

A partir dos resultados da aplicação das diversas metodologias utilizadas, foi elaborado um quadro-síntese contendo os prós e contras de cada método (ver Tabela 2). Como se pode perceber, cada uma das técnicas urtilizadas apresentam aspectos positivos e negativos. No entanto, elas se complementam e podem fornecer um panorama geral e fiel do ambiente avaliado.

Tabela 2 - Aspectos positivos e negativos das técnicas de APO utilizadas

\begin{tabular}{|c|c|c|c|c|}
\hline \multirow{2}{*}{ Aspectos } & \multicolumn{4}{|c|}{ Técnicas de APO } \\
\hline & Entrevista Informal & Questionário & Walkthrough & Vistoria Técnica \\
\hline Positivos & $\begin{array}{l}\text { Conhecer o } \\
\text { funcionamento da } \\
\text { escola }\end{array}$ & $\begin{array}{l}\text { Identificar as reais } \\
\text { necessidades dos } \\
\text { usuários em relação } \\
\text { ao ambiente }\end{array}$ & $\begin{array}{l}\text { Aferição das } \\
\text { condições de } \\
\text { funcionamento da } \\
\text { escola; adequação } \\
\text { dos ambientes, e } \\
\text { adaptações feitas em } \\
\text { relação ao projeto } \\
\text { original. }\end{array}$ & $\begin{array}{l}\text { Visão imparcial dos } \\
\text { aspectos negativos } \\
\text { e positivos. }\end{array}$ \\
\hline Negativos & $\begin{array}{l}\text { A opinião do } \\
\text { dirigente pode } \\
\text { mascarar alguns } \\
\text { problemas de } \\
\text { funcionamento da } \\
\text { escola. Assim o uso } \\
\text { individual dessa } \\
\text { ferramenta torna a } \\
\text { avaliação superficial. }\end{array}$ & $\begin{array}{l}\text { Método vulnerável a } \\
\text { erros, conforme } \\
\text { discordâncias } \\
\text { apresentadas nos } \\
\text { gráficos (Figuras } 4 \text { e } \\
\text { 5). }\end{array}$ & & $\begin{array}{l}\text { Alguns aspectos } \\
\text { encontrados são } \\
\text { divergentes em } \\
\text { relação aos } \\
\text { identificados nas } \\
\text { entrevistas e } \\
\text { questionários }\end{array}$ \\
\hline
\end{tabular}




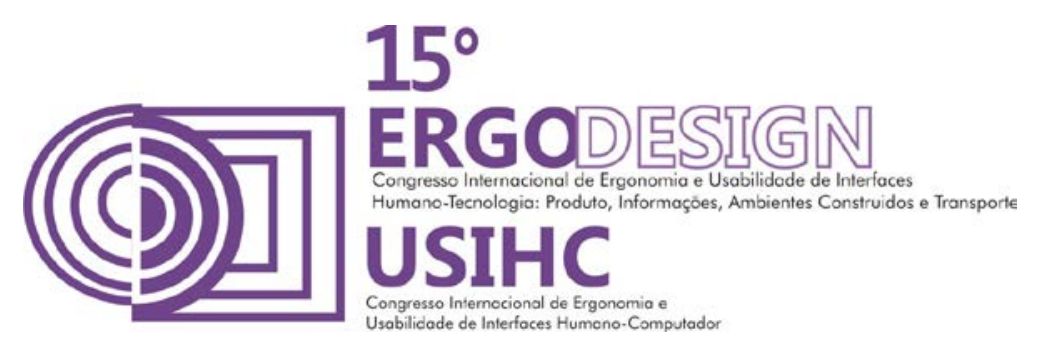

Assim, de acordo com as informações obtidas em cada técnica pode-se afirmar que os métodos Entrevista e Questionário alicerçam o conhecimento e o entendimento do espaço escolar e, o Walkthrough e a Vistoria Técnica comprovam o funcionamento da escola no dia a dia e os problemas decorrentes de aspectos Estético-Compositivos; Técnico-construtivos; Contextual-Ambientais e Programático-Funcionais. Considerando que o propósito da avaliação é a obtenção de resultados concisos, claros e imparciais, o método de observação utilizando a técnica de Walkthrough se mostrou mais eficiente.

\section{CONSIDERAÇÕES FINAIS}

Através das análises realizadas neste artigo, pode-se afirmar que a utilização da metodologia de Avaliação Pós-Ocupação através da abordagem multimétodos pode contribuir para uma avaliação do desempenho espacial de edifícios escolares em relação aos aspectos EstéticoCompositivos; Técnico-construtivos; Contextual-Ambientais e Programático-Funcionais. O uso em conjunto das técnicas de entrevistas, questionários, walkthrough e vistoria técnica se mostrou eficaz para identificar a qualidade espacial de um ambiente educacional.

Muitos dos problemas elencados resultam da falta de preocupação no processo de envelhecimento da edificação, bem como a falta de um programa de manutenção preventiva e corretiva durante sua utilização. Muitos problemas poderiam ser identificados e sanados a partir de avaliações sistemáticas no local, através da utilização de métodos e técnicas de avaliação Pós-Ocupação. Nesse contexto, as informações obtidas com a pesquisa, além de contribuir para gerar diretrizes de projeto, ressaltam a importância do emprego da abordagem multimétodos visando subsidiar projetos de intervenção com qualidade.

\section{REFERÊNCIAS BIBLIOGRÁFICAS}

ABATE, Tania Pietzschze. Instrumentos de avaliação Pós-Ocupação (APO) adaptados a préescolas com deficiência física, auditiva e visual. 491 f. Tese (Doutorado). Pós-Graduação em Arquitetura e Urbanismo. Universidade de São Paulo, São Paulo, 2011.

BRASIL. Ministério da Educação. Secretaria de Educação Básica. Parâmetros básicos de infraestrutura para instituições de educação infantil. Brasília: MEC, SEB, 2006.

CAMPOS, Maria Malta; ROSEMBERG, Fúlvia. Critérios para um atendimento em creches que respeite os direitos fundamentais das crianças - 6. ed. Brasília: MEC, SEB, 2009.

ISSA, Maíra Piccolotto; POLTRONIERI, Julyane Pereira; ORNSTEIN, Sheila Walbe. O caso da E.E. FERNANDO GASPARIN na cidade de São Paulo. 2008. Disponível em: $<$ <ww.usp.br/nutau/CD/82.pdf>. Acesso em: 08 de jan. de 2015.

ORNSTEIN, Sheila Walbe; MARTINS, Claudia Alonso. Arquitetura, Manutenção e Segurança de ambientes escolares: um estudo aplicativo de APO. 1997. Disponível em: <http://seer.ufrgs.br/ambienteconstruido/article/view/3308>. Acesso em: 19 jun. 2014.

RHEINGANTZ, Paulo Afonso; AZEVEDO, Giselle Arteiro; BRASILEIRO, Alice; ALCANTARA, Denise de; QUEIROZ, Mônica. Observando a qualidade do lugar: procedimentos para a avaliação pósocupação. Rio de Janeiro: Universidade Federal do Rio de Janeiro, PROARQ. 2009.

RODRIGUES, Antonio Carlos Baccarin. Desempenho funcional e espaços arquitetônicos de três escolas municipais de Chapecó. 107 f. Dissertação (Mestrado). Departamento de Engenharia Civil, Universidade Federal de Santa Catarina, Florianópolis - SC, 2006.

ROMÉRO, Marcelo de Andrad; ORNSTEIN, Sheila Walbe. AVALIAÇÃo PÓS-OCUPAÇÃO: Métodos e Técnicas Aplicados à Habitação Social. Porto Alegre: Coleção Habitare/Finep, 2003. 